\title{
Multidimensional Thinking of Systemic Functional Linguistics
}

\author{
Hongjie Zhang \\ Xi’an International Studies University, Xi'an, Shaanxi, 710128
}

Keywords: Systemic Functional Linguistics, Multidimensional Thinking

\begin{abstract}
Systemic functional linguistics, a language discipline based on certain philosophical ideas, plays an important role in the academic development of today's world. The development of systemic functional linguistics is also long-term, and today many people's cognition of systemic functional linguistics is relatively shallow, and some are even unheard of, but learning system functional linguistics is very helpful to the overall development. Therefore, in order to achieve the goal, it is necessary to first increase the cognition of systemic functional linguistics and clarify the meaning of development.
\end{abstract}

\section{Introduction}

With the development and progress of the times, new ideas, ideas, technologies and many other aspects have flooded into the society. Under the promotion of these excellent factors, not only has the society developed rapidly, but people's daily lives have also undergone earth-shaking Variety. Systemic functional linguistics, as a product of social and human development, evolved from the anthropological tradition. The main difference between this discipline and other disciplines is that it emphasizes the sociality of language users and is based on language practice. Application, thus providing better services for human survival and development. Systemic language function, first appeared in the United Kingdom, was founded by the famous British linguist Halliday. From the perspective of theory, systemic linguistics means that language is used as a tool on the basis of social attributes. Practice activities, not just in terms of thinking, at the same time, pay more attention to the analysis of individual languages, and verify theories through observation and statistical means. That is to say, systemic functional linguistics is based on the humanity and sociality of language, paying attention to the communication of language and improving the behavioral ability of social people to engage in society.

\section{Characteristics of system linguistics}

Systemic linguists attach great importance to the social function of language and how to realize these social functions, so systematic linguists concentrate on discovering and describing various language variants resulting from different social situations and speaker situations, and these variants. The relationship with social function. Therefore, systematic linguistics is most easily applied to sociolinguistics and language teaching, and it is also closely related to stylistics. This feature is the fundamental difference between systemic linguistics and transformational grammar: systematic linguistics studies language from a social perspective, does not pay attention to the psychological basis of language; transforms generative grammar to study language from a psychological perspective, but asks the close relationship between language and society .

Systemic linguistics considers language as a way of "doing things," not "knowledge." After Saussure distinguishes between "language" and "speech", similar to this division, Chomsky distinguishes between "language ability" and "language use". Halliday's distinction is "language behavior potential" and "actuality". Language behavior". The difference between the two is not in "speech", they all think that speech is what the speaker actually said. The difference is how to know "language." Halliday believes that the so-called "language" is what the speaker "can do", and the so-called "speech" is what the speaker "actually does". Chomsky's "knowledge" is the psychological category of language, "language ability" is the characteristic of the individual; Halliday's "doing 
things" approach belongs to the social category of language, that is, the relationship between language and the environment, "the language behavior potential "Belongs to the characteristics of a language community. This is an important sign that systemic functional linguistics differs from transformative linguistics and many other linguistic factions.

System linguistics pays more attention to the description of individual languages and individual variants, and considers that such description itself is one of the purposes of linguistics, not to discover the universal phenomenon of language. The conversion generation grammar pays more attention to the common phenomenon of language discovery. Investigating individual languages is only a means. In Halliday's words, only the differences between languages, especially the cultural differences embodied in these differences, are really important. Understanding and mastering these differences will help overcome the communication barriers they create. At this point, the systemic functional linguistics and the transformational generative school are undoubtedly tit for tat.

\section{Cognitive Study of Systemic Functional Linguistics}

Systemic functional linguistics was founded by the British linguist Halliday, and its linguistic theory consists mainly of three aspects: first, drawing on the anthropological achievements of Malinowski, due to Malinoff In the process of anthropological research,sky found that the language is different. Due to the influence of topography and humanities, language can be transmitted through translation, and the biggest obstacle to language translation is the different cultural background. Secondly, drawing on Foss's linguistic theory, it is concluded in the language theory of Firth that the use of language is inseparable from the environment. Different speaking environments use different languages, and the meaning they want to express is also It will be different. Thirdly, drawing on Wolff's linguistic relevance theory, through the study of the language and cultural relations of American Indians in Wolff's linguistic relevance theory, it is found that the internal composition of language and the users who use the language are between There is a very close relationship between philosophical view and cognitive structure. Thus, the systemic functional linguistics created by Halliday is based on these three theories and further developed to create a complete system.

Systemic functional linguistics itself is a huge subject, and there are many classifications within it. In addition, systemic functional linguistics focuses on the emphasis and attention to language systems and language functions, so it can be said from this aspect. The system language function is divided into two parts, one is system linguistics and the other is functional linguistics. Although the systemic functional linguistics was founded by the British Halliday, it originated in the ancient Greek period, but it is in the stage of the development of ancient Greek civilization, influenced by the language concepts of Protagoras and Plato. It has developed, and it also proposes that the language has three major functions, namely conceptual function, interpersonal function and textual function. The so-called language concept function refers to people using language to discuss the world, things and the surrounding situation, language The interpersonal function refers to the use of language to maintain the relationship between people, the use of language to communicate with others to establish and maintain good interpersonal relationships, and the discourse function of language refers to people using How to organize good language information in the process of language, maintain the relationship between information, and also show the communication environment of the sender and the sender's actual communication environment.

After understanding the development background and classification of systemic functional linguistics, it is necessary to understand the characteristics of system linguistics in order to truly understand systemic functional linguistics from a more in-depth perspective. Systemic functional linguistics belongs to the branch of functional linguistics. It has the following characteristics: The first feature is that systemic functional linguistics is more comprehensive in the field of linguistics research. The scope of its research involves many aspects. Linguistics, lexicology, grammar, contextual research and other aspects, this remarkable feature makes systemic functional linguistics more comprehensive in theory; the second feature is that systemic functional linguistics is practical and can be used In many aspects, such as foreign language teaching, translation studies, stylistic 
analysis, computer applications, etc., it can be said that the practicality is more extensive; the third feature is that the systemic functional linguistics has a long history in China; fourth The characteristic is that systemic functional linguistics has strong social use and better helps people in the development of society, interpersonal communication can better deal with and promote two-way development.

\section{Development prospects of systemic functional linguistics}

Systemic functional linguistics, as described above, is an evolving genre that is a major trend in linguistic research today. In addition, from the perspective of systemic functional linguistics itself, there are still many areas that need to be researched and developed. With the development of modern science and technology, some problems that could not be studied before have now been studied. Therefore, from the current situation, systemic functional linguistics has broad prospects for development.

The theory of systemic functional linguistics itself requires more in-depth research and needs to be continuously developed. Areas to be further studied include: research on physical systems; research on value systems; research on the relationship between language and context; research on the relationship between meaning systems and culture; register research; genre research; textual cohesion and coherence research.

Systemic functional linguistics itself is developed in combination with other fields and disciplines, such as the combination of sociology, anthropology, and ethnology. Therefore, the interdisciplinary research of systemic functional linguistics is one of the main driving forces of its development. The fields involved include: critical discourse analysis research; teaching reference function grammar research; cognitive linguistics research; mathematical linguistics research; language and other symbols Systematic relationship research; description of other languages, etc.

Halliday has always believed that although linguistics cannot replace applied linguistics, the life of linguistics lies in its application, is recognized in applications, and develops in applications. In the application of systemic functional linguistics, the following aspects are also needed: language teaching; stylistics; translation studies; artificial intelligence; children's language development.

Pragmatics has developed rapidly in recent years and has become a major research area worldwide. But Halliday said: "In my opinion, pragmatics seems to be just another name for discourse semantics. I don't just talk about this term in terms of terms. For me, semantic theory should include both systems and processes. Just as grammar theory includes both systems and processes. So we don't need something called 'pragmatics'." Obviously, Halliday believes that systemic functional linguistics includes pragmatics, and that it is only a part of systemic functional semantics, and that it cannot be separated from another part. According to this, Halliday believes that an independent pragmatic branch should not be established. In China, Zhang Delu and Zhu Yongsheng also wrote that the pragmatics and systemic functional linguistics have complementary relationships, that is, the research perspective and scope of pragmatics, research methods and results can be used to enrich the theory of systemic functional linguistics.

\section{Conclusion}

Systemic functional linguistics is a general linguistics and applied linguistic theory. Its language model is based on meaning, and its significance is very important in theoretical construction. The process of constructing theory is to turn language theory into a higher-level meaning system of human beings. By discussing the abstraction of theory from the meaning dimension and process, we can examine the overall organization and specific embodiment of the meaning system such as language. In the theoretical abstraction system network, one or more meaning dimensions can be examined, and multiple meaning dimensions are interlaced to form a multi-dimensional meaning space, which can be two-dimensional or multi-dimensional through matrix presentation. Matrices provide an important perspective for identifying the meaningful addresses of a particular system. Based on the above understanding, we will understand why meaning is the focus of theoretical 
study of systemic functional linguistics, and will further understand the importance of meaning in the theoretical construction of linguistic systems and grammatical analysis.

\section{References}

[1] An Mei. Research on Chinese and Foreign Discourse under the Theory of Systemic Functional Linguistics [J]. Language Construction, 2016, (23).

[2] Chen Yumin, Huang Guowen. "Meaning" in Systemic Functional Linguistics [J]. Foreign Language Teaching, 2016, (05).

[3] Zheng Haiyan. Analysis of the development and theoretical framework of systemic functional linguistics [J]. China National Expo, 2016, (08).

[4] Liu Xiaoyu, Huo Lin. The Insufficiency of Systemic Functional Linguistics [J]. Journal of Beijing City University, 2006, (02).

[5] Zhang Changqi.The Application of Systemic Functional Linguistics in Poetic Interpretation [J].Journal of Social Science of Harbin Normal University.2015,(02). 